\title{
Erroneous Tense Patterns in the English Used by Telugu People
}

Dr. P. Lakshmi Narasa Dasu

Asst. Professor of English

Government Degree College

Eluru, West Godavari District

Andhra Pradesh, India

Dr. Rama Rao Chevula

Asst. Professor of English

GITAM (Deemed to be University)

Hyderabad, Telangana, India

rama9c@gmail.com

\begin{abstract}
This research paper attempts to explore certain deviations in the usage of English tenses by some Telugu people who require perfection at grammatical level of wording. By explaining the nature of deviant tense forms which can be treated as errors in teaching and learning pedagogical setting, this paper aims to identify the problematic typical erroneous patterns in their English grammar. Identification of underlying influences and pattern-wise understanding of the consequent deviant forms are very important to design remedial workbooks for specific needs of teaching and learning. Hence some frequent erroneous English tense patterns used by Telugu learners are briefed in this study. This study is assumed to be useful to many people with Telugu background to rectify their usage of ungrammatical English.
\end{abstract}


Keywords: ESL, Morphology Syntax, Phonics, Structures. Introduction

According to the present globalized communicative scenario, English has become the chief lingua-franca all over the world. As the situations demand many people are eager to attain perfection in their English communication. As a part of learning and usage, learners belonging to certain linguistic identity, present some similar erroneous patterns. Identification of such patterns would be useful for understanding the nature of deviations from genuine and original forms of a language. According to Corder (1982) errors in second or foreign language are useful in teaching.

According to the Systemic Functional Grammar by Halliday \& Matthiessen (2004), language is a stratified system comprising semantics, lexico-grammar, phonology and phonetics as the linguistic strata which are collectively operated by the principle called 'realization'. When learners make errors in their usage of target language, it is evident that the realization from semantic content to lexico-grammatical content is unclear and so allows erroneous patterns in the usage of language.These error patterns can be the result of first language and/or other learning problems. Hence, for pedagogical purpose, the language teaching perspectives require attention of realization from the semantic content to the lexicogrammatical content. The study attempts to provide an explanation of erroneous patterns in the English used by Telugu people who learn English as a second or foreign language. The main focus of this research paper is at the level of grammatical stratum, especially in relation to the usage of tense in English.

As the study needs empirical evidence, the data was collected from 20 Telugu people who have English as second language in their graduation; they generally use English according to their situational requirements. The sentences illustrated in this paper are based 
on the analysis of the data. The following are the pattern-wise descriptions towards the findings.

I. Errors of Substitution

\section{A. Present Continuous Tenseinstead of Simple Present Tense}

1. Incorrect: Daily, I am going to my office.

Correct: Daily, I go to my office.

2. Incorrect: My son is drinking milk every day.

Correct: $\quad$ My son drinks milk every day.

3. Incorrect: We are visiting church on Sundays regularly.

Correct: We visit church on Sundays regularly.

Explanation: Mother tongue influence is the main cause of the substitutive pattern of errors; because, in Telugu, present continues tense is synonymous ${ }^{1}$ with simple present tense and more frequent than simple present form. Unless there is a particular contextual demand, the aspectual distinction is not expressed in Telugu; butin case of clearing ambiguity, sometimes the distinction also is identified through tonic prominence. Because of this synonymous aspect, there is much possibility of impact on similar usage in English.

B. Present Continuous Tense instead of Past Continuous Tense

1. Incorrect: When I went to his house, he is watching TV.

Correct: $\quad$ When I went to his house, he was watching TV.

2. Incorrect: she is cooking food. Then you called her

Correct: $\quad$ she was cooking food. Then you called her

3. Incorrect: $\quad$ Yesterday, theyare playing cricket, then...

Correct: $\quad$ Yesterday, they were playing cricket, then...

\footnotetext{
${ }^{1}$ But Simple present tense is not synonymous with present continues tense in Telugu.
} 
Explanation: Regarding continuous aspect of time, Telugu grammatical structure doesn't include distinction of past and present in relation to time. The semantic realization depends on some adverbials of time at lexico-grammatical level; in addition to that, context of situation plays an important role in identifying the sense of time aspect

C. Simple Past Tense instead ofPresent Perfect Tense

1. Incorrect: I completed the work just now.

Correct: $\quad$ I have completed that work just now.

2. Incorrect: Recently, they bought a new house.

Correct: $\quad$ Recently, they have bought a new house.

3. Incorrect: Today we wrote an exam Correct: Today we have written an exam

Explanation: Regarding past and perfective aspect of time, Telugu lexico-grammatical stratum shows no difference between completed actions and just completed actions. As in the earlier case, context of situation and adverbials of time are determining factors of time aspects of the events.

\section{Action Verbs instead of Stative Verbs}

1 Incorrect: I am thinking that he is a teacher

Correct: $\quad$ I think that he is a teacher

2 Incorrect: She is believing her friend

Correct: $\quad$ She believes her friend

3. Incorrect: I am always wishing your success

Correct: I always wish your success

Explanation: Regarding the substitution pattern of action verbs in place of stative verbs, mother tongue influence is very obvious in observation. In English, stative verbs are always used in simple present tense since they imply emotions or opinions as a state of mind rather 
than movements or actions. In Telugu, both actions and states are structurally realized in continuous form; they are context dependent for their determination of situational meaning.Hence, in erroneous English, simple present tense is substituted with present continuous tense.

The above errors of substitutive nature are very much connected to Telugu as mother tongue influence. The problems mentioned here can be rectified by paying attention to the specified erroneous patterns. Apart from these, some other patterns are also found in this study. The following deviant patterns can be rectified with regular practice. Let us look into these patterns.

II. Errors of Redundancy

\section{A. Redundant Use of Auxiliary Verb}

1. Incorrect:

I am talked to him.

Correct:

I talked to him.

2. Incorrect:

She is went to college.

Correct:

She went to college.

3. Incorrect:

They are played cricket.

Correct:

They played cricket

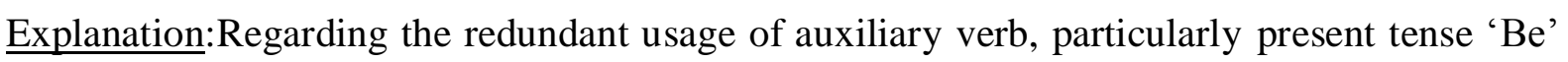
form verbs, i.e. am, is and are redundantly used especially in simple past tense sentences. This unwanted addition generally follows its subject. This type of redundant addition is observable in many cases of erroneous usage of English sentences.

III. Inappropriate Agreement
A. Lack of Tense Agreement

1. Incorrect:

I did not went to school 
Correct: $\quad$ Idid not go to school

2. Incorrect: $\quad$ you did not enjoyed the party.

Correct: $\quad$ youdid notenjoy the party

3. Incorrect: He did notmet me

Correct: $\quad$ He did notmeet me

Explanation: The simple past structure in negative sentences of English basically forms with agreement between the past auxiliary verb did and present form of main verb in clause. In spite of not much frequent as other erroneous patterns, the type of errors with double past wording is also found in this study.

\section{B. Lack of Subject and Verb Agreement}

1. Incorrect: He dancewell.

Correct: $\quad$ He danceswell.

2. Incorrect: She go to market every day.

Correct: $\quad$ She goes to market every day.

3. Incorrect: The bus reach the station by the evening.

Correct: $\quad$ The bus reaches the station by the evening.

Explanation:The concord between subject and verb is structurally very important in simple present form of English sentences. The verbal inflection marker s/es correlates to the subject of the clause in terms of number in the lexico-grammatical structure of simple present in English language. In the erroneous patterns identified in this research, this particular pattern of errors is observed in many cases. 


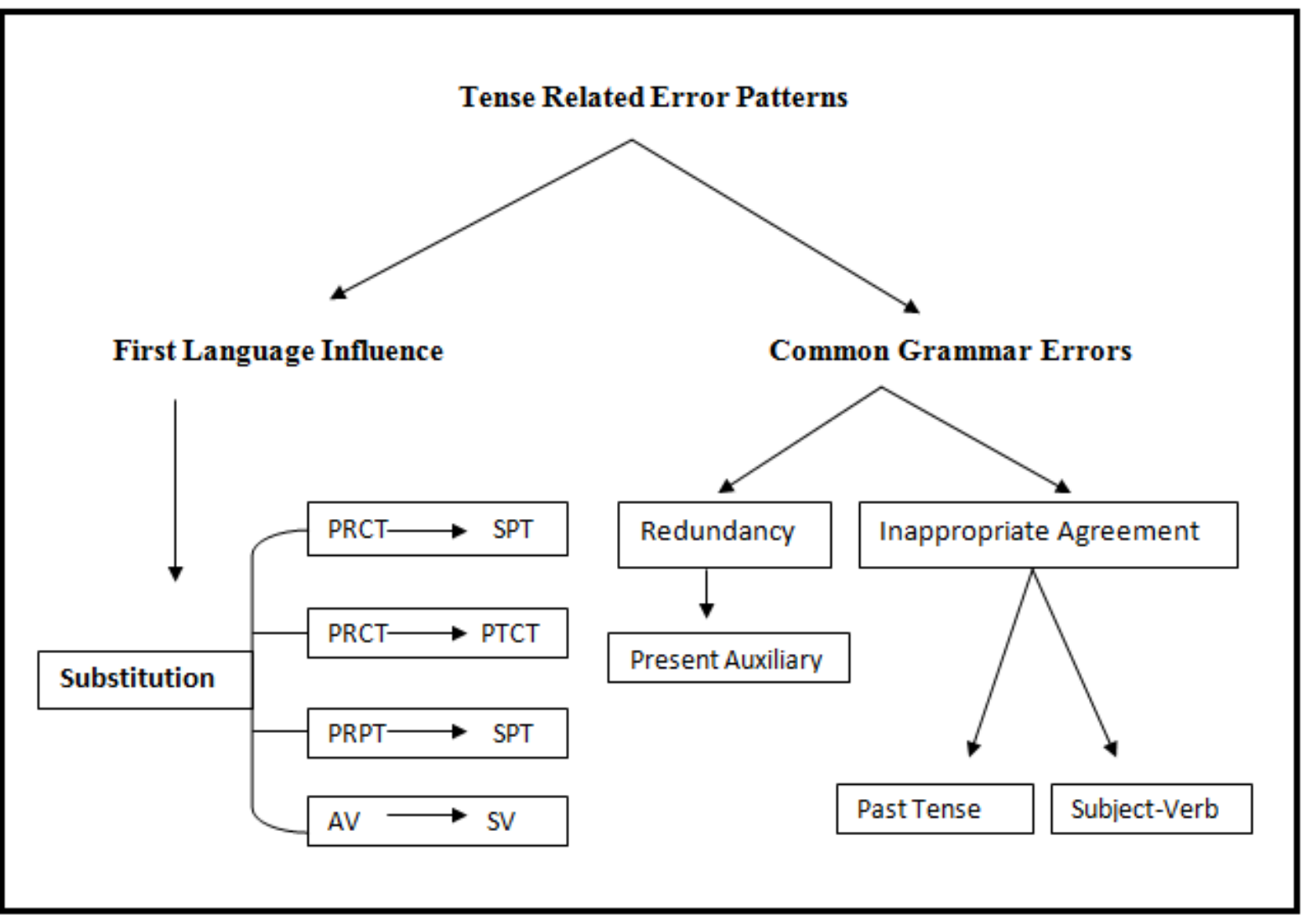

Fig. 1. The diagram provides the consolidated graphical representation of the patterns Note: the abbreviations used in the diagram are to be understood as the following.

PRCT: Present Continuous Tense

PTCT: Past Continuous Tense

SPT: Simple Present Tense

PRPT: Present Perfect Tense

AV: Action Verb

SV: Stative Verb

Conclusion

The findings of this study reveal that major part of the errors made by English learning Telugu people belong to mother tongue influence. The study attempted to explore certain erroneous patterns involved in the first language influence. The study also brought 
into light about some other erroneous patterns related to redundant and inappropriate wording inclusions. As pedagogical implications, this study suggests to focus on the interfering aspects which cause erroneous patterns in English tense usage. Moreover, based on these research findings, worksheets can be designed according to the needs in teaching and learning process. Identification of the nature of deviations from originality and their relevant causes can ease the process towards teaching and learning solutions. 


\section{References}

Corder, S. P. (1982).Error Analysis and Interlanguage. London: Oxford University Press.

Halliday, M.A.K., \& Matthiessen, C.M.I.M. (2004). An Introduction to Functional Grammar. 3d ed. London: Arnold.

Halliday, M.A.K, \& Greaves, W. (2008). Intonation in the Grammar of English. UK: Unit 6, The Village, 101 Amies St, London, SW11 2JW.

Krishnamurti, B. (n.d.). A Grammar of Modern Telugu. 1985. Delhi.

Ramakrishna Reddy, B. (1986). Localist Studies in Telugu syntax. Hyderabad.

Subrahmanyam, P. S. (1974). An Introduction to Modern Telugu. Sivakami Printers. Annamalainagar.

Lakshmi Narasa Dasu, P. (2012). Some aspects of grammar and tonicity: a comparison between Telugu and English Occasional Papers in Linguistics. Vol. 16, 2012, EFL University Press, EFLU.

Lakshmi Narasa Dasu, P. (2016). A study of Telugu intonation; English intonation vis-à-vis Telugu intonation. Ph.D Dissertation. Hyderabad: EFLU.

Rama Rao, C. (2017). A Syntactic Account of Some Errors in the English of Telugu Learners. Ph.D Dissertation. Hyderabad: EFLU. 